\title{
PVD TiN and CrN Coated Austempered Ductile Iron: Analysis of Processing Parameters Influence on Coating Characteristics and Substrate Microstructure
}

\author{
Diego Alejandro COLOMBO, ${ }^{1,2) *}$ María Dolores ECHEVERRÍA, ${ }^{1)}$ Osvaldo Julio MONCADA ${ }^{1,2)}$ and \\ Juan Miguel MASSONE ${ }^{2)}$
}

1) Mechanical Technology Group, School of Engineering, Universidad Nacional de Mar del Plata, Av. J. B. Justo 4302, (B7608FDQ) Mar del Plata, Argentina.E-mail: diegocolombo@fi.mdp.edu.ar, mechever@fi.mdp.edu.ar,moncada @fi.mdp.edu.ar 2) Metallurgy Division, INTEMA-CONICET, School of Engineering, Universidad Nacional de Mar del Plata, Av. J. B. Justo 4302, (B7608FDQ) Mar del Plata, Argentina. E-mail: massonej@fi.mdp.edu.ar

(Received on May 12, 2011; accepted on September 20, 2011)

\begin{abstract}
This work studies the influence of the PVD processing parameters on the characteristics of TiN and CrN coatings deposited on $\mathrm{ADI}$ substrates, austempered at $360^{\circ} \mathrm{C}$, with different nodule counts and surface roughnesses. Coatings were applied by arc ion plating using an industrial reactor and different sets of parameters, with BIAS voltages, arc currents, chamber pressures and substrate temperatures varying from -100 to $-250 \mathrm{~V}, 60$ to $65 \mathrm{~A}, 0.7$ to $2.8 \mathrm{~Pa}$ and 280 to $450^{\circ} \mathrm{C}$, respectively. The effect of the different depositions conditions on the substrates microstructure was also analyzed. The existing phases, preferred orientation, surface topography, film thickness, hardness and adhesion of each coating were determined. The retained austenite content and hardness of each substrate were computed before and after coating deposition.

The results obtained indicate that the different deposition conditions and coating materials evaluated do not generate significant changes neither in the resulting topography nor in the coating adhesion, which can be related to indices between HF1 and HF2. Coating adhesion was not affected by different substrate roughnesses. The combined reduction of BIAS voltage, arc current and chamber pressure leads to a decrease of TiN growth rate and hardness, while high substrate temperatures promotes an increase in TiN and $\mathrm{CrN}$ growth rates. Substrate temperatures around $300^{\circ} \mathrm{C}$ with deposition times of up to 240 min do not promote noticeable changes on the ausferritic microstructure, while temperatures of $400^{\circ} \mathrm{C}$ and above translate into a clear microstructural deterioration, even for short deposition times.
\end{abstract}

KEY WORDS: austempered ductile iron; TiN; CrN; PVD processing parameters.

\section{Introduction}

The increasing use of austempered ductile iron (ADI) together with the greater demands in terms of corrosion and wear resistances have promoted the development and application of different surface treatments on this material. ${ }^{1-3)}$

A common and highly relevant variable in most surface treatments is processing temperature. The temperature range applied to ADI surface treatment is very broad, from $200^{\circ} \mathrm{C}$ in surface coating by physical vapor deposition $(\mathrm{PVD})^{4,5}$ to the melting temperature of the treated material in electron beam surface melting. ${ }^{\text {) }}$ However, ADI exposure to high temperature during long periods of time may cause changes in the ausferritic microstructure and negatively affect the mechanical behavior of the material. ${ }^{7}$ )

Studies conducted by the authors of this work ${ }^{8)}$ with PVD-TiN coatings deposited on ductile iron substrates with different nodule counts and austempering temperatures, using an industrial reactor and under processing parameters specifically selected for this material presented acceptable coating characteristics regarding film thickness, hardness and adhesion, without causing significant deterioration of the ausferritic microstructure. The arithmetic average roughness of the uncoated and coated samples increased as nodule count decreased within the range evaluated. No influence of nodule count and austempering temperature was observed on coating adhesion.

In spite of this, it must be taken into account that coating properties rely on substrate characteristics (cleaning prior to deposition, microstructure, surface topography, mechanical properties, and physicochemical compatibility with the coating material) as well as on processing parameters (chamber pressure, incidence angle and gas flow distribution, current density, BIAS voltage, and substrate temperature, among others). ${ }^{9)}$

On this basis and in order to produce major advances, this work studies the influence of the PVD processing parameters on the characteristics of TiN and $\mathrm{CrN}$ coatings deposited on ADI substrates, austempered at $360^{\circ} \mathrm{C}$, with different nodule counts and surface roughnesses. Coatings were 
applied by the arc ion plating technique using an industrial reactor and different sets of processing parameters. The effect of the different depositions conditions on the substrates microstructure was also analyzed. The existing phases, preferred orientation, surface topography, film thickness, hardness and adhesion of each coating were determined. The retained austenite content and hardness of each substrate were computed before and after coating deposition.

\section{Experimental Procedures}

\subsection{Substrate Material and Samples Preparation}

The experimental material was ductile iron produced in a $55 \mathrm{~kg}$ middle-frequency induction furnace $(3 \mathrm{KHz})$. The furnace was charged with pig iron, steel scrap, graphite, and ferrosilicon.

The charge was melted and superheated to $1550^{\circ} \mathrm{C}$. The liquid metal was extracted and treated in separate ladles using the two step method. Nodularising was carried out in the first ladle using a $1.40 \%$ of FeSiMg $(6 \% \mathrm{Mg})$ and the sandwich method. Inoculation was performed during the transfer to the second ladle, by adding a $0.65 \%$ of $\mathrm{FeSi}(75 \%$ Si) to the stream.

The melt was poured into silica sand vertical moulds designed to yield 4 and $6 \mathrm{~mm}$ thick plates, and into Y-blocks of 13 and $25 \mathrm{~mm}$, in order to obtain different nodule counts. The chemical composition of the material (wt. \%), analyzed by a Baird DV6 optical emission spectrometer, was as follows: C: 3.4; Si: 2.7; Mn: 0.21; S: 0.008; P: 0.027; Mg: 0.033 and Fe balanced. CE: 4.3.

The plates and Y-blocks were cut and machined in order to obtain prismatic samples of nominal dimensions $30 \times$ $30 \times 4 \mathrm{~mm}$ approximately. The samples were subjected to an austempering heat treatment, which consisted in an austenitising at $910^{\circ} \mathrm{C}$ for $120 \mathrm{~min}$, an austempering in a salt bath at $360^{\circ} \mathrm{C}$ for $90 \mathrm{~min}$, and a subsequent air cooling to room temperature. An austempering temperature of $360^{\circ} \mathrm{C}$ was selected for promoting a microstructure with high retained austenite content, ${ }^{10)}$ rendering the substrates more sensitive to a possible degradation quantification.

Finally, the ADI samples were subjected to a manual polishing using 100, 400 and 1000 grit sizes $\mathrm{SiC}$ waterproof paper to obtain different surface roughnesses.

\subsection{PVD Coating Process}

The ADI substrates were thoroughly degreased, ultrasonically cleaned, rinsed with alcohol and dried with warm air before deposition. $\mathrm{CrN}$ and $\mathrm{TiN}$ hard coatings were applied in an industrial reactor by arc ion plating (AIP) using different sets of processing parameters, as can be seen in Table 1. Inside the reactor, and prior to deposition, substrates were cleaned once again by bombardments with energetic ions, thereby eliminating oxides debris and other contaminants.

In processes $\mathrm{A}, \mathrm{B}, \mathrm{C}$ and $\mathrm{D}$ the substrates were coated with TiN, while in processes $\mathrm{E}$ and $\mathrm{F}$ with $\mathrm{CrN}$. The parameters of process A were applied in a previous work. ${ }^{8)}$ In process $C$, the substrates were placed on a support, used as a backup piece, to allow heat dissipation and thus reduce the effects of the coating process on the ausferritic microstructure.
Table 1. Deposition parameters of $\mathrm{TiN}$ and $\mathrm{CrN}$ coatings.

\begin{tabular}{lrrrrrr}
\hline \multicolumn{1}{c}{ Process } & A & B & C & D & E & F \\
\hline Coating material & TiN & TiN & TiN & TiN & CrN & CrN \\
Substrate-target distance $[\mathrm{mm}]$ & 200 & 200 & 200 & 200 & 200 & 200 \\
Substrate BIAS voltage $[\mathrm{V}]$ & -250 & -150 & -250 & -100 & -175 & -250 \\
Arc current [A] & 65 & 60 & 65 & 60 & 65 & 60 \\
Chamber pressure $[\mathrm{Pa}]$ & 2 & 1.5 & 2 & 0.7 & 2.8 & 0.7 \\
Substrate temperature $\left[{ }^{\circ} \mathrm{C}\right]$ & 300 & 280 & 300 & 450 & 300 & 400 \\
Deposition time $[\mathrm{min}]$ & 120 & 120 & 240 & 45 & 45 & 90 \\
Mounting mode & hanging hanging on support hanging hanging hanging \\
\hline
\end{tabular}

Table 2. Nodule count and Vickers hardness of ADI substrates.

\begin{tabular}{ccc}
\hline $\begin{array}{c}\text { Casting } \\
\text { thickness }[\mathrm{mm}]\end{array}$ & $\begin{array}{c}\text { Nodule count } \\
{\left[\mathrm{nod} / \mathrm{mm}^{2}\right]}\end{array}$ & $\begin{array}{c}\text { Hardness } \\
{\left[\mathrm{HV}_{30}\right]}\end{array}$ \\
\hline 25 (Y-block) & 265 & 330 \\
13 (Y-block) & 494 & 348 \\
6 (plate) & 593 & 366 \\
4 (plate) & 1056 & 385 \\
\hline
\end{tabular}

\subsection{Substrates and Coatings Characterization}

The values of average nodule count corresponding to each casting thickness were determined by optical microscopy and digital image processing, taking a nodule diameter of $5 \mu \mathrm{m}$ as threshold value. Table 2 lists the nodule count and Vickers hardness (30 Kg load) of the different ADI substrates. Based on comparisons with charts, nodularity exceeded $90 \%$ in all casting thicknesses.

X-ray diffraction (XRD) was performed for phase identification in substrates and coatings. $\mathrm{Cu} K \alpha$ radiation $(\lambda=$ $1.5418 \AA$ ) at $40 \mathrm{kV}$ and $40 \mathrm{~mA}$ was utilized. XRD patterns were recorded in a $2 \theta$ range from $30^{\circ}$ to $90^{\circ}$ in steps of $0.02^{\circ}$ and with a counting time of 1 second per step.

Optical microscopy was utilized for the metallographic characterization of the substrates.

The retained austenite content of the substrates was determined by processing their XRD patterns with the software PowderCell. Coatings were removed by manual polishing with $\mathrm{SiC}$ waterproof paper to record the XRD patterns of the substrates after deposition.

The hardness of the ausferritic matrices, before and after coating deposition, and the hardness of the coated samples were determined by conducting Knoop hardness tests, using a $15 \mathrm{~g}$ load.

The surface topography of the coated and uncoated samples was assessed by analyzing the arithmetic average roughness $(\mathrm{Ra})$. A surface roughness tester (Taylor Hobson Surtronic 3+) was used within an evaluation length of $4 \mathrm{~mm}$ (cut-off, $0.8 \mathrm{~mm}$ ).

Coatings thickness was measured on fractured cross sections micrographs, obtained by SEM.

Coating adhesion was evaluated using the Rockwell-C adhesion test, ${ }^{11)}$ using a $150 \mathrm{~kg}$ load.

\section{Results and Discussion}

\subsection{Phase Identification}

Figure 1 illustrates some diffraction patterns of the samples analyzed before and after coating deposition. The pat- 
a
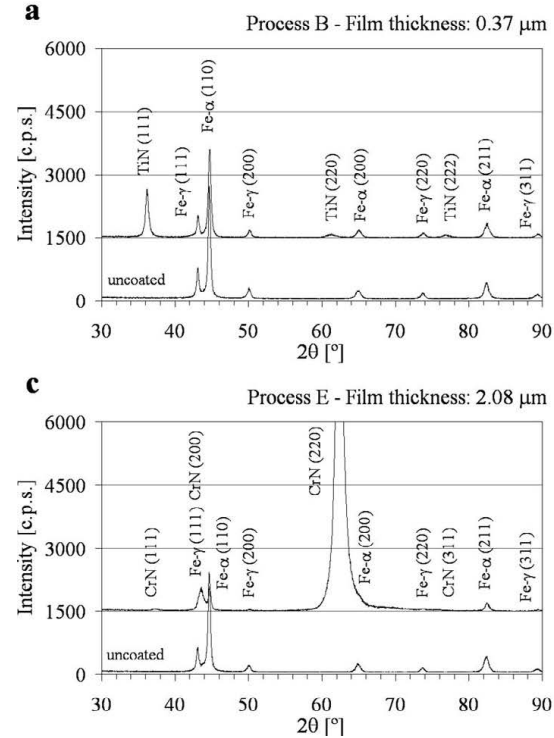

b

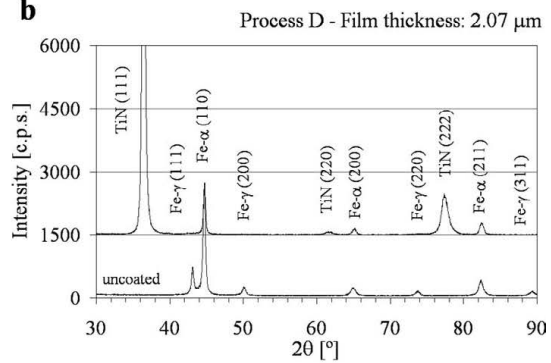

Fig. 1. XRD patterns of $1056 \mathrm{nod} / \mathrm{mm}^{2}$ uncoated and coated ADI samples: (a) Process B, (b) Process D, (c) Process E.

terns of the coated samples revealed the main diffraction peak of the coatings and some peaks of the phases belonging to the substrates, since the penetration depth of the X-rays is greater than the coatings thickness.

Independently of the processing parameters utilized, TiN and $\mathrm{CrN}$ coatings were grown with a preferred orientation of (111) and (220) planes parallel to their surface, respectively. A lower intensity of the coating peaks was observed as film thickness decreased, as illustrated in Figs. 1(a) and 1(b) for different film thickness of the TiN coated samples. Variations in film thickness, as shown below, were evidenced by modifying the PVD processing parameters.

\subsection{Substrates Microstructure}

Figure 2 compares the microstructure of ADI substrates before and after coating deposition.

Figures 2(a) and 2(b) illustrate the starting ausferritic microstructures of high and low nodule count respectively, which were composed of acicular ferrite and metastable austenite of high carbon content. It can be observed that a thinner casting thickness promoted a higher nodule count and a finer ausferritic microstructure.

Substrates temperatures in the range $280-300^{\circ} \mathrm{C}$ with deposition times between 45 and $240 \mathrm{~min}$, did not promote noticeable changes in the substrates microstructure, as can be seen in Fig. 2(c). In agreement with this observation, the substrates revealed practically null or slight changes in the retained austenite content and no hardness variations after deposition, as shown in Table 3. In contrast, substrates temperatures of 400 and $450^{\circ} \mathrm{C}$ with deposition times up to 90 min caused a clear deterioration of the ausferritic microstructure, characterized by a loss of the acicular morphology and the appearance of recrystallized ferrite and carbides (Fig. 2(d)), a drastic decrease of the retained austenite content and a hardness variation (Table 3 ).

The surface hardness increment evidenced in samples coated at temperatures above $400^{\circ} \mathrm{C}$ (process $\mathrm{D}$ and $\mathrm{F}$ in Table 3) can be explained by the precipitation of carbides from the metastable austenite during ADI degradation. ${ }^{7,12)}$

The use of a backup piece in process $\mathrm{C}$, allowed a mark-
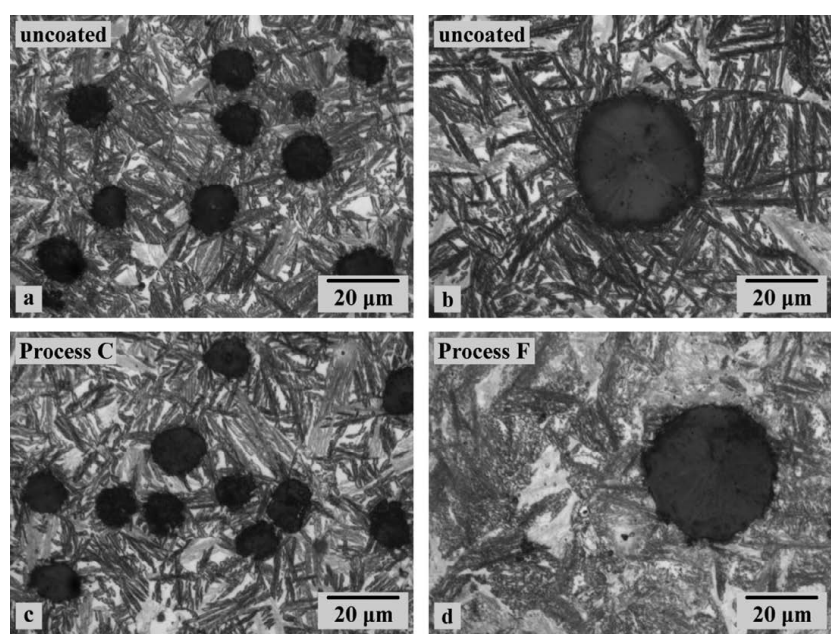

Fig. 2. Microstructure of ADI substrates before and after coating deposition: (a) $1056 \mathrm{nod} / \mathrm{mm}^{2}$ [casting thickness, $4 \mathrm{~mm}$ ], (b) $265 \mathrm{nod} / \mathrm{mm}^{2}$ [casting thickness, $25 \mathrm{~mm}$, (c) $1056 \mathrm{nod} / \mathrm{mm}^{2}$ - Process C, (d) $265 \mathrm{nod} / \mathrm{mm}^{2}$ - Process F.

Table 3. Retained austenite content and Knoop hardness of ADI substrates before and after coating deposition.

\begin{tabular}{|c|c|c|c|c|c|c|}
\hline \multicolumn{2}{|c|}{ Process } & \multirow[t]{2}{*}{$\begin{array}{c}\text { Nodule } \\
\text { count } \\
{\left[\operatorname{nod} / \mathrm{mm}^{2}\right]}\end{array}$} & \multicolumn{2}{|c|}{$\begin{array}{l}\text { Retained austenite } \\
\text { content [vol \%] }\end{array}$} & \multicolumn{2}{|c|}{$\begin{array}{l}\text { Hardness } \\
{\left[\mathrm{HK}_{0.015}\right]}\end{array}$} \\
\hline & & & Before & After & Before & After \\
\hline A & $300^{\circ} \mathrm{C}$ & 494 & 30.0 & 29.4 & $369 \pm 18$ & $366 \pm 11$ \\
\hline TiN & $120 \mathrm{~min}$ & 1056 & 32.1 & 31.5 & $417 \pm 19$ & $414 \pm 16$ \\
\hline B & $280^{\circ} \mathrm{C}$ & 494 & 30.3 & 30.2 & $369 \pm 18$ & $368 \pm 15$ \\
\hline TiN & $120 \mathrm{~min}$ & 1056 & 29.9 & 29.8 & $417 \pm 19$ & $420 \pm 21$ \\
\hline $\mathrm{C}$ & $300^{\circ} \mathrm{C}$ & 494 & 34.6 & 32.2 & $369 \pm 18$ & $371 \pm 26$ \\
\hline TiN & $240 \mathrm{~min}$ & 1056 & 36.0 & 33.6 & $417 \pm 19$ & $416 \pm 22$ \\
\hline D & $450^{\circ} \mathrm{C}$ & 265 & 29.3 & $<1$ & $375 \pm 35$ & $532 \pm 41$ \\
\hline TiN & $45 \mathrm{~min}$ & 1056 & 31.9 & $<1$ & $401 \pm 28$ & $560 \pm 37$ \\
\hline $\mathrm{E}$ & $300^{\circ} \mathrm{C}$ & 593 & 30.8 & 30.3 & $394 \pm 13$ & $390 \pm 23$ \\
\hline $\mathrm{CrN}$ & $45 \mathrm{~min}$ & 1056 & 28.8 & 28.4 & $417 \pm 19$ & $418 \pm 22$ \\
\hline $\mathrm{F}$ & $400^{\circ} \mathrm{C}$ & 265 & 29.3 & $<1$ & $375 \pm 35$ & $538 \pm 36$ \\
\hline $\mathrm{CrN}$ & $90 \mathrm{~min}$ & 1056 & 31.9 & $<1$ & $401 \pm 28$ & $558 \pm 31$ \\
\hline
\end{tabular}


edly increase in the deposition time without causing any significant deterioration of the ausferritic microstructure.

As a consequence, it can be assumed that processing temperatures of around $300^{\circ} \mathrm{C}$ with deposition times of up to $240 \mathrm{~min}$ are suitable for the treatment of ADI substrates. Nevertheless, the analysis of the effects of the processing parameters will be completed only after the evaluation of coatings characteristics.

\subsection{Surface Topography}

Figure 3 compares the effect of the nodule count and the surface finishing on the surface roughness of the uncoated and coated samples, while Fig. 4 compares the effect of the different processing parameters and coatings materials on the surface roughness of the samples.

\subsubsection{Uncoated Samples (Substrates)}

As can be seen in Fig. 3, the substrates with finer surface finishings (1 000 and 400 grit sizes) displayed an increase in the Ra values as nodule count decreased. This fact can be ascribed to the coarsening of the matrix structure as nodule count decreases (see Fig. 2) as well as to the partial or complete graphite removal of certain surface nodules during the polishing stage. On the other hand, the substrates with coarser surface finishing (100 grit size) displayed similar Ra values for the different nodule counts, since the size of the grooves generated during polishing masks the aforementioned effect of Ra variation with nodule count.

\subsubsection{Coated Samples}

The deposition processes altered the surface topography

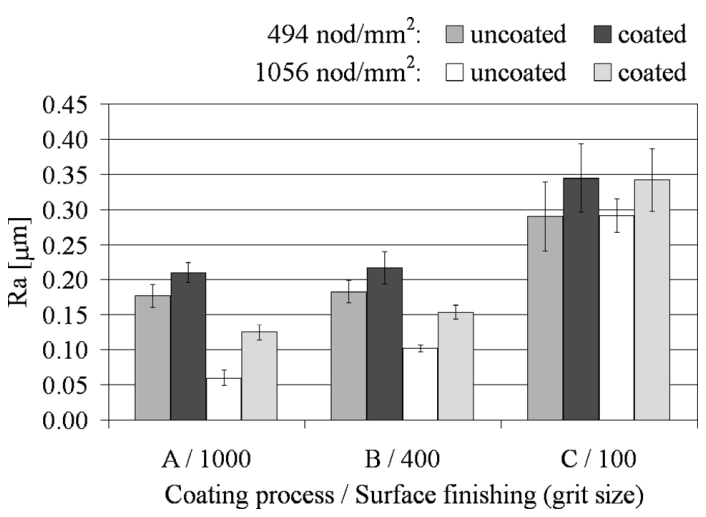

Fig. 3. Effect of nodule count and surface finishing on the surface roughness of the uncoated and TiN coated ADI samples.

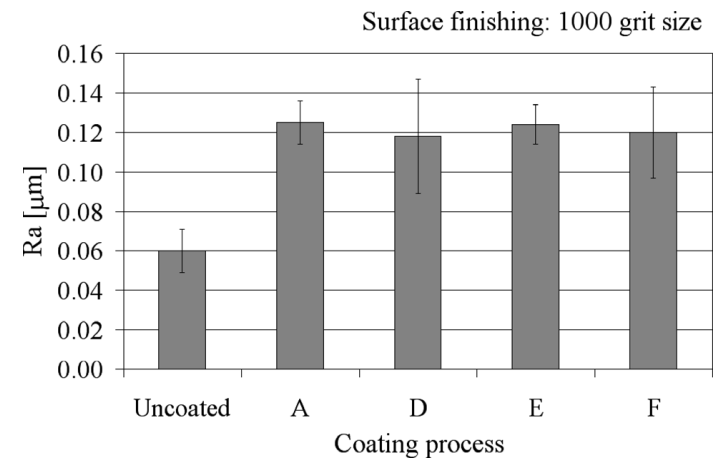

Fig. 4. Surface roughness of $1056 \mathrm{nod} / \mathrm{mm}^{2}$ uncoated and coated ADI samples. Effect of different deposition conditions and coating materials. of the samples leading to an increase in Ra in all the cases, as illustrated in Figs. 3 and 4. According to other studies, ${ }^{13,14)}$ these alterations can be assigned to the attachment of $\mathrm{Ti}$ or $\mathrm{Cr}$ droplets to the growing film, which are generated on the target surface during arc evaporation.

Figures 3 (low nodule count samples coated using processes $\mathrm{A}$ and $\mathrm{B}$ ) and 4 show that the different processing parameters and coating materials utilized did not produce significant changes in the resulting topography, at least within the range of parameters and substrate roughnesses evaluated. Therefore, it can be asserted that the resulting topography of the coated samples is mainly dependent on the initial substrate surface roughness.

\subsection{Coatings Characteristics}

\subsubsection{Film Thickness}

The thickness of the TiN coatings deposited under different processing conditions ranged from 0.37 to $3.68 \mu \mathrm{m}$, as can be seen in Table 4. As an example, Fig. 5 shows a fractured cross section micrograph of a TiN coated sample, used to measure the film thickness.

For similar substrate temperatures and deposition times, a combined reduction of BIAS voltage, arc current and

Table 4. Film thickness and Knoop hardness of ADI coated samples.

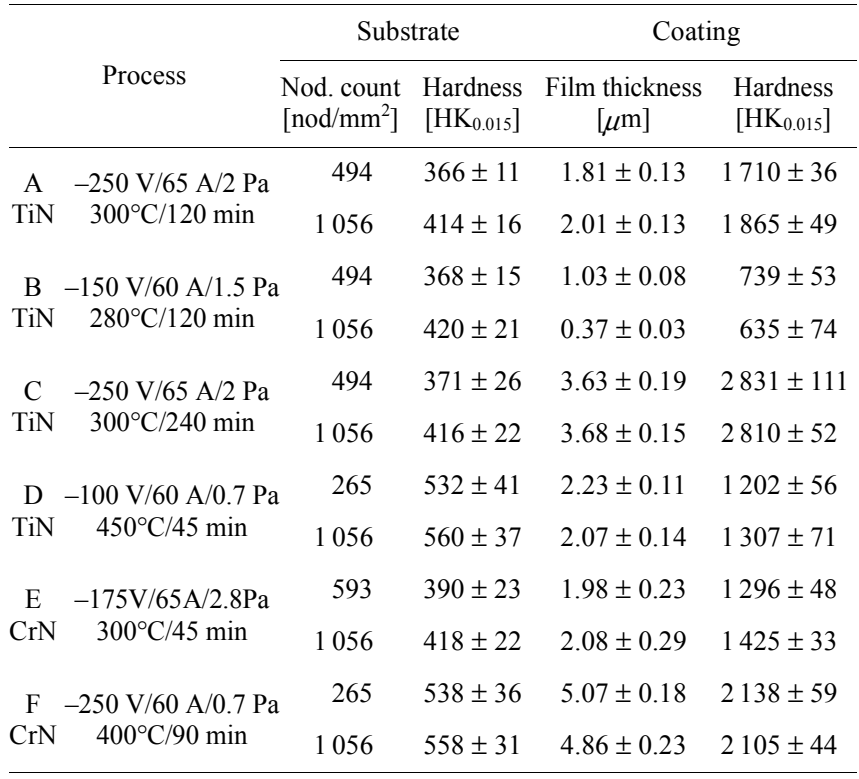

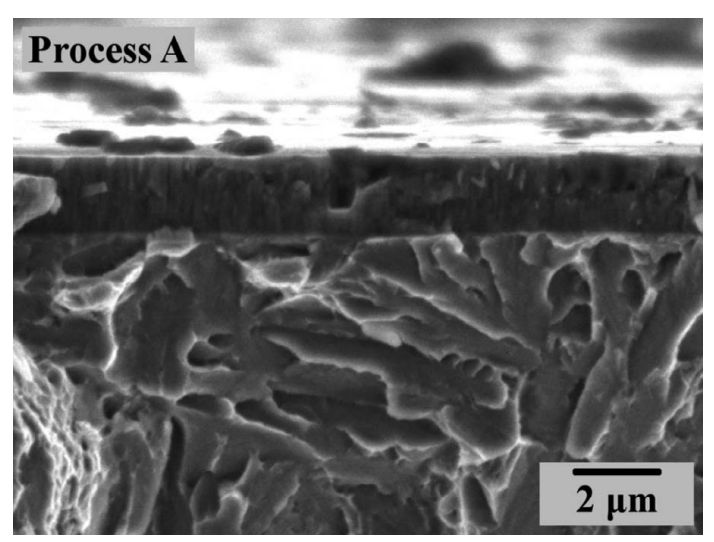

Fig. 5. SEM micrograph showing a fractured cross section of a $1056 \mathrm{nod} / \mathrm{mm}^{2}$ ADI sample coated using process A. 
chamber pressure (comparing processes A and B), led to a reduction of the film growth rate. Conversely, high substrate temperatures (comparing processes A and D), promoted an increase in the film growth rate. It can be seen that the same film thickness was obtained by reducing the deposition time about 3 times when the temperature was increased from 300 to $450^{\circ} \mathrm{C}$.

The thickness of the $\mathrm{CrN}$ coatings came up to $5.07 \mu \mathrm{m}$, being evident that an increase in the substrate temperature and deposition time (comparing processes $\mathrm{E}$ and $\mathrm{F}$ ), led to an increase in the film thickness over $100 \%$.

\subsubsection{Hardness}

The hardness of the $\mathrm{TiN}$ and $\mathrm{CrN}$ coated samples ranged from $635 \mathrm{HK}$ to $2872 \mathrm{HK}$ and from 1296 to $2138 \mathrm{HK}$ respectively, as can be seen in Table 4 .

The indentation response of a coated sample depends on the film thickness and the characteristics of substrates and coatings. ${ }^{15)}$ For a given applied load, a lower film thickness leads to a greater influence of the substrate on the hardness of the coated sample, as can be seen in Fig. 6 .

By comparing process $\mathrm{A}$ and $\mathrm{D}$, it can be observed that

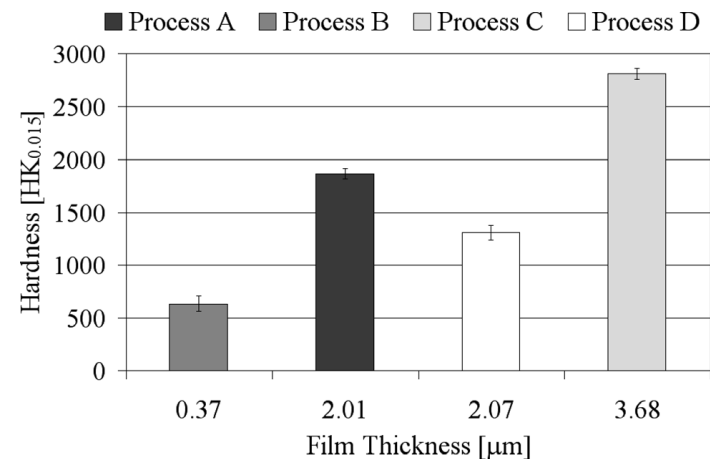

Fig. 6. Hardness vs. film thickness for the $1056 \mathrm{nod} / \mathrm{mm}^{2} \mathrm{TiN}$ coated ADI samples.
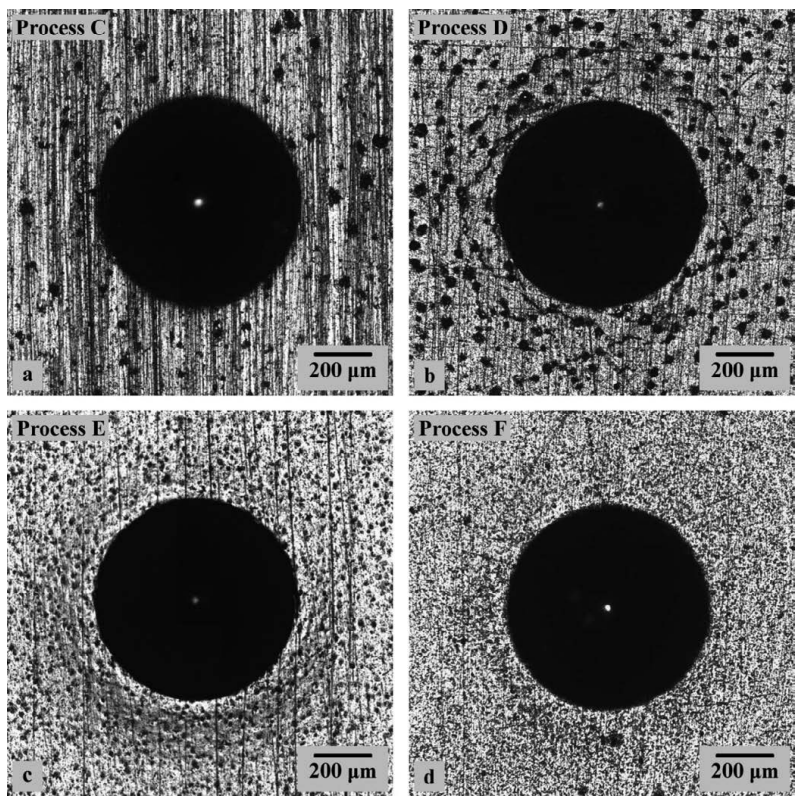

Fig. 7. Imprints on ADI coated samples after Rockwell-C adhesion test: (a) $494 \mathrm{nod} / \mathrm{mm}^{2}$ - Process C, (b) $265 \mathrm{nod} / \mathrm{mm}^{2}$ - Process D, (c) $593 \mathrm{nod} / \mathrm{mm}^{2}$ - Process E, (d) $1056 \mathrm{nod} / \mathrm{mm}^{2}-$ Process F. the reduction of BIAS voltage, arc current and chamber pressure combined with a high substrate temperature, led to a decrease in the TiN coating hardness.

\subsubsection{Adhesion Strength Quality}

The adhesion strength quality of TiN and $\mathrm{CrN}$ coatings to ADI substrates can be related to indices ranging from HF1 to HF2. No delaminations occurred in any case. It is worth noticing that different deposition conditions and coating materials yielded no effect on coatings adhesion. The different substrates characteristics, regarding hardness, nodule count and surface roughness, exerted no effect within the ranges evaluated. Figure 7 illustrates, as an example, some imprints resulting from the Rockwell-C adhesion test.

\section{General Remarks}

By comparing the effects of the TiN deposition processes on the substrates microstructure and coatings characteristics, it can be noted that the processes carried out at temperature of $300^{\circ} \mathrm{C}$, with deposition times of up to $240 \mathrm{~min}$, did not promote noticeable changes on the substrates microstructure and led to good film quality as regards film thickness, hardness and adhesion strength. Despite the fact that the deposition at $280^{\circ} \mathrm{C}$ during $120 \mathrm{~min}$ inhibited almost completely the retained austenite transformation, the low values of BIAS voltage, arc current and chamber pressure utilized resulted in a film growth rate significantly lower. On the other hand, the deposition at $450^{\circ} \mathrm{C}$ led to a clear deterioration of the ausferritic microstructure, even for a deposition time of $45 \mathrm{~min}$. This high temperature combined with low values of BIAS voltage, arc current and chamber pressure caused poor film quality in terms of hardness.

As far as $\mathrm{CrN}$ coatings are concerned, the process carried out at $400^{\circ} \mathrm{C}$ with a deposition time of $90 \mathrm{~min}$ also led to a complete deterioration of the substrates microstructure, but promoted good film quality in terms of film thickness, hardness and adhesion strength. In contrast, the processing parameters used in the deposition at $300^{\circ} \mathrm{C}$ during $45 \mathrm{~min}$, provided acceptable film properties without altering the ausferritic microstructure.

\section{Conclusions}

PVD TiN and CrN coatings were deposited by arc ion plating, using different sets of processing parameters, on ADI substrates austempered at $360^{\circ} \mathrm{C}$ with different nodule counts and surface roughnesses. TiN and $\mathrm{CrN}$ coatings showed a preferred orientation of (111) and (220) planes parallel to their surface, respectively, independently of the processing parameters utilized.

The different deposition conditions and coating materials evaluated did not produce significant changes in the surface topography of the coated samples, which resulted mainly dependent on the initial substrate surface roughness.

The thickness of the TiN coatings ranged from 0.37 to $3.68 \mu \mathrm{m}$, while that of the $\mathrm{CrN}$ coatings came up to $5.07 \mu \mathrm{m}$. For substrate temperatures of around $300^{\circ} \mathrm{C}$, the TiN growth rate was reduced by jointly reducing the BIAS voltage, the arc current and the chamber pressure. Substrate temperatures of $400^{\circ} \mathrm{C}$ and above, led to a marked increase 
in the $\mathrm{TiN}$ and $\mathrm{CrN}$ growth rates.

Knoop hardness of the $\mathrm{TiN}$ and $\mathrm{CrN}$ coated samples increased with film thickness, values ranged from 635 to $2872 \mathrm{HK}$ and from 1296 to $2138 \mathrm{HK}$, respectively. A reduction in BIAS voltage, arc current and chamber pressure combined with a high substrate temperature $\left(450^{\circ} \mathrm{C}\right)$ led to a decrease of the TiN coating hardness.

The adhesion strength quality of the TiN and $\mathrm{CrN}$ coatings can be related to indices ranging from HF1 to HF2. Different processing conditions and coating materials yielded no effect on adhesion. The different substrates characteristics, regarding hardness, nodule count and surface roughness, exerted no effect within the ranges evaluated.

Depositions carried out at temperatures close to $300^{\circ} \mathrm{C}$, with deposition times of up to $240 \mathrm{~min}$, did not promote noticeable changes on the substrates microstructure, while those performed at temperatures of $400^{\circ} \mathrm{C}$ and above, caused a clear deterioration of the ausferritic microstructure, even for short deposition times.

\section{REFERENCES}

1) A. Amirsadeghi, M. H. Sohi and S. F. K. Bozorg: J. Iron Steel Res. Int., 15 (2008), 86

2) A. Pepe, P. Galliano, S. Ceré, M. Aparicio and A. Durán: Mater. Lett., 59 (2005), 2219.

3) A. Roy and I. Manna: Mater. Sci. Eng. A, 297 (2001), 85.

4) C.-H. Hsu, K.-L. Chen and J.-H. Lu: Surf. Coat. Technol., 203 (2008), 868.

5) C.-H. Hsu, J.-K. Lu and R.-J. Tsai: Mater. Sci. Eng. A, 398 (2005), 282.

6) M. Heydarzadeh Sohi, G. Karshenas and S. M. A. Boutorabi: $J$. Mater. Process. Technol., 153-154 (2004), 199.

7) J. M. Massone, R. E. Boeri and J. A. Sikora: Int. J. Cast Met. Res., 9 (1996), 79

8) D. A. Colombo, M. D. Echeverría, O. J. Moncada and J. M. Massone: ISIJ Int., 51 (2011), 448.

9) D. M. Mattox: ASM Handbook, Vol. 5, Surface Eng., ASM Int., Ohio, (1994), 538.

10) G. Francucci, J. Sikora and R. Dommarco: Mater. Sci. Eng. A, 485 (2008), 46.

11) W. Heinke, A. Leyland, A. Matthews, G. Berg, C. Friedrich and E. Broszeit: Thin Solid Films, 270 (1995), 431.

12) A. Gazda: J. Therm. Anal. Calorim., 102 (2010), 923.

13) J.-W. Lee, J.-G. Duh and J.-H. Wang: Surf. Coat. Technol., 168 (2003), 223.

14) M.-H. Shiao and F.-S. Shieu: Thin Solid Films, 386 (2001), 27

15) A. M. Korsunsky, M. R. McGurk, S. J. Bull and T. F. Page: Surf. Coat. Technol., 99 (1998), 171. 